\title{
Metabolic engineering and transcriptomic analysis of Saccharomyces cerevisiae producing $p$-coumaric acid from xylose
}

\author{
Gheorghe M. Borja ${ }^{1}$ (1), Angelica Rodriguez ${ }^{1,4}$, Kate Campbell², Irina Borodina' ${ }^{1}$ Yun Chen ${ }^{2}$ \\ and Jens Nielsen ${ }^{1,2,3,4^{*}}$ (1)
}

\begin{abstract}
Background: Aromatic amino acids and their derivatives are valuable chemicals and are precursors for different industrially compounds. $p$-Coumaric acid is the main building block for complex secondary metabolites in commercial demand, such as flavonoids and polyphenols. Industrial scale production of this compound from yeast however remains challenging.

Results: Using metabolic engineering and a systems biology approach, we developed a Saccharomyces cerevisiae platform strain able to produce $242 \mathrm{mg} / \mathrm{L}$ of $p$-coumaric acid from xylose. The same strain produced only $5.35 \mathrm{mg} / \mathrm{L}$ when cultivated with glucose as carbon source. To characterise this platform strain further, transcriptomic analysis was performed, comparing this strain's growth on xylose and glucose, revealing a strong up-regulation of the glyoxylate pathway alongside increased cell wall biosynthesis and unexpectedly a decrease in aromatic amino acid gene expression when xylose was used as carbon source.
\end{abstract}

Conclusions: The resulting $S$. cerevisiae strain represents a promising platform host for future production of $p$-coumaric using xylose as a carbon source.

Keywords: Saccharomyces cerevisiae, Transcriptome, $p$-Coumaric acid, Xylose, RNAseq

\section{Background}

Aromatic amino acids (AAAs) and their derivatives (AAADs) are valuable chemicals, that also serve as precursors for a variety of other industrially relevant compounds. Currently these compounds have a global market of $\sim \$ 8$ billion, which is projected to reach $\sim \$ 20$ billion by $2020[1,2]$. The majority of AAADs (see Table 1), such as flavonoids and polyphenols, are produced from either non-renewable fossil fuels or by plant extraction, which suffers from either non-sustainable production or low yields. To reduce the dependency on fossil fuels for this process, whilst meeting the growing demand for AAADs,

\footnotetext{
*Correspondence: nielsenj@chalmers.se

${ }^{2}$ Department of Biology and Biological Engineering, Chalmers University of Technology, 41296 Gothenburg, Sweden

Full list of author information is available at the end of the article
}

renewable sources of biomass have subsequently been explored as substrate for AAAD production.

So far, the biotechnology industry has investigated use of prokaryotes for AAAD production, for example, in modified strains of Escherichia coli [3-5], Pseudomonas putida [6], and Corynebacterium glutamicum [7, 8], with glucose being used as the primary carbon source. Exploratory studies in plants have also proven it to be possible to produce a diverse array of AAADs in tobacco [9], tomato [10] and Arabidopsis thaliana [11]. To date however, the highest titers of $2.4 \mathrm{~g} / \mathrm{L}$ of $p$-coumaric acid have been achieved using microbial fermentation with the yeast Saccharomyces cerevisiae [12]. This yeast is therefore considered a promising cell factory platform for AAAD production, in particular due to its ability to express functional $\mathrm{P} 450$ proteins that are required for synthesising many AAADs, a feat that can otherwise be challenging when prokaryotes are used. This is well 
Table 1 Examples of microbial production of aromatic amino acid derivatives (AAAD)

\begin{tabular}{|c|c|c|c|c|c|c|}
\hline Product & Titer & Yield & Organism & Feedstock & Culture style & Reference \\
\hline trans-Cinnamic acid & $151 \mathrm{mg} / \mathrm{L}$ & $0.016 \mathrm{~g} / \mathrm{g}$ & E. coli & Arabinose & Batch (shake flask) & {$[68]$} \\
\hline Styrene & $29 \mathrm{mg} / \mathrm{L}$ & $1.44 \mathrm{mg} / \mathrm{g}$ & S. lividans & Glucose & Batch (shake flask) & {$[69]$} \\
\hline p-Hydroxystyrene & $2.52 \mathrm{~g} / \mathrm{L}$ & $0.027 \mathrm{~g} / \mathrm{g}$ & P.putida & Glucose & Fed-batch & {$[70]$} \\
\hline p-Hydroxybenzoic acid & $2.3 \mathrm{~g} / \mathrm{L}$ & $0.11 \mathrm{~g} / \mathrm{g}$ & E. coli & Glucose, xylose & Fed-batch & {$[71]$} \\
\hline p-Aminobenzoic acid & $215 \mathrm{mg} / \mathrm{L}$ & N.E. & S. cerevisiae & Glycerol, ethanol & Fed-batch & {$[72]$} \\
\hline p-Coumaric acid & $2.4 \mathrm{~g} / \mathrm{L}$ & $0.013 \mathrm{~g} / \mathrm{g}$ & S. cerevisiae & Glucose & Batch & {$[12]$} \\
\hline Resveratrol & $0.8 \mathrm{~g} / \mathrm{L}$ & $\mathrm{NE}$ & S. cerevisiae & Glucose, ethanol & Fed-batch & [35] \\
\hline
\end{tabular}

$N E$ not estimated

illustrated by the implementation of a commercial production of resveratrol by an engineered yeast strain, a process that has been established by the biotech company Fluxome AS and later acquired by Evolva AG.

Saccharomyces cerevisiae has proven a robust cell factory platform for diverse industrial applications, being able to produce food and beverage supplements [13, 14], rotavirus-like-particles [15], antibodies [16], therapeutic proteins [17], sesquiterpenes [18], isoprenoids [19], succinic acid [20], amongst other industrially relevant chemicals. Extensive tools have also been developed, such as CRISPR-Cas gene editing, for rapid and effective genetic manipulation of this yeast [21-23]. Moreover, it has proven possible to reconfigure $S$. cerevisiae's metabolism using evolutionary engineering such as adaptive laboratory evolution [24]. With this approach, yeast is genetically adapted in response to adverse conditions based on the principles of natural selection. Using deep sequencing and reverse engineering, causal mutations can then be introduced into a parent strain, to confer its resistance to stress conditions such as high temperatures [25], osmotic stress [26], low $\mathrm{pH}$ [27], or toxic products [28]. Taken together, these attributes make $S$. cerevisiae a promising candidate for use as a platform strain for the production of AAADs [29-31].

Previous studies that have used $S$. cerevisiae for the production of AAA and AAADs have been performed by eliminating feedback control at critical points in the shikimate pathway, which is responsible for the synthesis of phenylalanine, tyrosine and tryptophan. This approach included using a mutated version of chorismate mutase, ARO7, and 3-deoxy-D-arabinoheptulosonate 7-phosphate (DAHP) synthase, ARO4, which enabled a 200-fold increase in AAAD compound production compared to the reference strain [32]. Many others AAADs such as resveratrol [33], naringenin [34], pinostilbene and pterostilbene [35] have also been successfully produced when glucose acts as the main carbon source. One valuable AAAD that belongs to a group of phenolic compounds commonly found in the plant kingdom is $p$-coumaric acid. This compound has been known to confer several health promoting physiological effects, such as antianxiety, anti-cancer, anti-oxidant, anti-inflammatory and anti-microbial activity [36]. $p$-Coumaric acid is also extensively employed respectively in the cosmetic, pharmaceutical and food industry, acting as a building block for more complex compounds such as noscapine [37]. Despite $p$-coumaric acid's wide-ranging uses, an economically viable and sustainable workflow for its production at industrial scale is lacking, with raw materials typically being an important point to consider in terms of process cost and design.

Here, yeast fermentations predominantly use $2 \%$ glucose as the carbon source, wherein the Crabtree effect, also known as overflow metabolism, is in effect. This phenomenon subsequently leads to the extracellular accumulation of energetically expensive metabolites during fermentation, such as acetate, ethanol, and glycerol, with decreased carbon allocation for the desired valueadded end product [38, 39]. One solution to avoid the Crabtree effect and redirect carbon flux towards biomass and AAAD production is by using non-fermentable sugars such as pentoses like xylose. After glucose, xylose is the second most abundant sugar in the world [40]. Subsequently, over the last 10 years, considerable efforts have been made by various research groups to transform xylose into a substrate for $S$. cerevisiae, thereby increasing its substrate range capability [40-42]. For example, Scalcinati et al. [43] developed a xylose utilizing strain (CMB.GS010) through adaptive evolution, which consumes xylose as the sole carbon source via the expression of PsXYL1 (xylose reductase, XR), PsXYL2 (xylitol dehydrogenase, XDH) and PsXYL3 (xylulose kinase, XK) from Pichia stipitis. The resulting strain had reduced overflow metabolism, with maximized carbon flux towards biomass production, and a biomass yield $\left(\mathrm{Cmol} \mathrm{Cmol}{ }^{-1}\right)$ of approximately four times that of glucose [43].

Here, using metabolic engineering and a systems biology approach, we generated a platform strain in S. cerevisiae (CMB.GS010) that utilises xylose as the sole carbon 
source for $p$-coumaric acid production. The resulting strain achieved a final $p$-coumaric acid titer of $242 \mathrm{mg} / \mathrm{L}$, representing a 45 -fold-increase over our condition with glucose. Furthermore, we used transcriptomic analysis to characterize the resulting strain under aerobic and controlled (carbon limited) fermentation conditions to determine how metabolism was altered when cells are grown on xylose instead of glucose.

\section{Results}

\section{Engineering a xylose utilization strain for the production of $p$-coumaric acid}

To investigate the physiological impact of the two carbon sources, glucose and xylose, and specifically how xylose affects $p$-coumaric acid production, we used the strain CMB.GS010 that had already been evolved to grow on xylose in a previous study [43]. The phenotype reported by Rodriguez et al. [44] resulted in a higher $p$-coumaric acid producer strain. Therefore, the genetic modifications of the best $p$-coumaric acid producer were performed in CMB.GS010 as a background strain. Specifically, to increase $p$-coumaric acid production, we first reduced by-product formation by knocking out both $A R O 10$ and PDC5. Then we expressed shikimate kinase II (aroL) from E. coli and tyrosine ammonia-lyase (TAL) from Flavobacterium johnsoniae, with tyrosine deamination enabling the production of $p$-coumaric acid [45]. Finally, to increase the overall carbon flux through the aromatic amino acid pathways, we overexpressed feedback-resistant versions of DAHP synthase and chorismate mutase producing the final strain used for characterisation, ST4274.

\section{Physiological characterization of $p$-coumaric acid producing strain under controlled conditions}

ST4274 was evaluated in small-scale bioreactors under well-defined, aerobic conditions, with two sets of batch cultivations carried out independently, containing $25 \mathrm{~g} / \mathrm{L}$ glucose and $25 \mathrm{~g} / \mathrm{L}$ xylose respectively (Fig. 1). Under our conditions, when glucose was used as the sole carbon source, a maximum concentration of $1.8 \pm 0.02 \mathrm{mg} / \mathrm{L}$ of $p$-coumaric was produced. And following glucose exhaustion, and a second (respiratory) growth phase (14-24 h) wherein the remaining organic acids were consumed in conjunction with the re-assimilation of ethanol, acetate, and glycerol, (produced by the cell during the glucose consumption phase), $p$-coumaric acid titer increased to $5.35 \pm 0.32 \mathrm{mg} / \mathrm{L}$. These values are notably less than previously reported, something which could be attributed to inter-strain differences between studies. Nonetheless, overall these results indicate that $p$-coumaric acid production occurs at higher levels
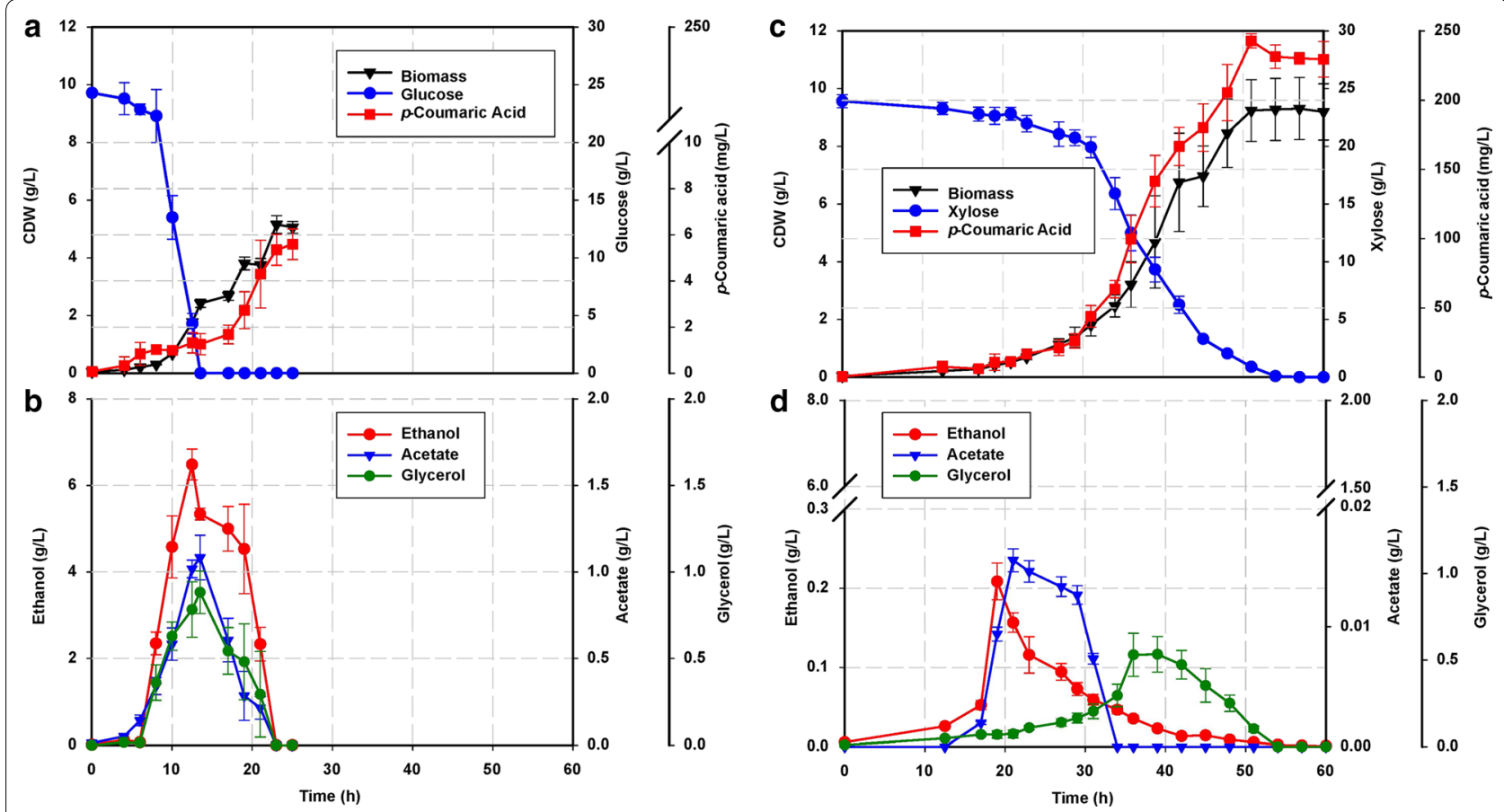

Fig. 1 Microbial production of $p$-coumaric acid in strain ST4274 during growth on: $\mathbf{a}$ glucose and $\mathbf{b}$ xylose in batch cultivations with an initial substrate concentration of $25 \mathrm{~g} / \mathrm{L}$. Top panels: substrate, biomass and $p$-coumaric acid. Bottom panels $\mathbf{c}$, $\mathbf{d}$ ethanol, acetate and glycerol concentrations $(n=4 \pm s d)$ 
during respiratory metabolism relative to fermentative metabolism.

To demonstrate that $p$-coumaric acid can be produced from xylose alone, a second set of cultivations were performed. Under these conditions, a maximum concentration of $242 \pm 5 \mathrm{mg} / \mathrm{L} p$-coumaric acid was produced after $60 \mathrm{~h}$ of cultivation (Fig. 1b). This represents a 45-fold increase compared with glucose conditions. During growth on xylose (Fig. 1b), it is also clear that only one growth phase occurs, similar to the growth profile of respiring cells and contrasting to cells grown on glucose that undergo fermentation followed by respiration after the diauxic shift. During growth on xylose, the secretion of organic acids was also observed to be ca. tenfold lower than during growth on glucose, reflecting a decreased effect of overflow metabolism. However, the maximum specific growth rate on xylose was also threefold lower (Table 2), similarly, the specific xylose uptake rate was ca. tenfold lower than the glucose uptake rate, indicating an overall decrease in carbon uptake and a concomitant reduction in biomass formation when xylose was used as the sole carbon source. Taken together, these results suggest that cells prefer glucose as a carbon source relative to xylose, however, as the titer of $p$-coumaric acid was 45 -fold higher under xylose conditions, despite the lower growth rate, xylose remained the optimal carbon source for $p$-coumaric acid production. This higher $p$-coumaric acid titer could be attributed to cells undergoing a respiratory like metabolism, wherein overflow metabolism does not occur, allowing for carbon flux to be utilised more efficiently for $p$-coumaric acid synthesis. This observation matches results seen for the second growth phase on glucose, as cells utilise ethanol following the post-diauxic shift, where activation of respiratory metabolism occurred alongside an increase in $p$-coumaric acid production (Table 3).

\section{Transcriptomic analysis}

To understand more clearly how cells respond to growth on xylose whilst producing $p$-coumaric acid, we sampled from the chemostat cultures and quantified the cell's transcriptional response to both carbon sources respectively, by performing RNA sequencing, differential expression and gene-set analysis (Fig. 2). Under xylose growth, upregulated GO-terms included those involved in transport activities, biosynthetic processes and membrane functions (Fig. 2a, d). GO-terms enriched in downregulated transcripts were related to carbohydrate metabolic processes and protein translation (Fig. 2a, d) with transcripts related to fungal cell wall, oxidationreduction processes and ammonium transport being significiantly differentially expressed when directionality of regulation was not considered (Fig. 2b). These results would suggest cells are adapting to xylose by optimising
Table 2 Physiological parameters for batch and chemostat cultivation

\begin{tabular}{|c|c|c|}
\hline & \multicolumn{2}{|l|}{ Substrate } \\
\hline & Glucose & Xylose \\
\hline \multicolumn{3}{|l|}{ Batch } \\
\hline$\mu_{\max }\left(h^{-1}\right)$ & $0.32 \pm 0.02$ & $0.11 \pm 0.01$ \\
\hline $\begin{array}{l}\text { Biomass concentration ( } C x \text { in } \\
\left.g_{D W} / L\right)\end{array}$ & $4.5 \pm 0.8$ & $12.16 \pm 0.9$ \\
\hline p-coumaric acid (mg/L) & $5.35 \pm 0.32$ & $242 \pm 12$ \\
\hline$Y_{S X}(g / g D W)$ & $0.13 \pm 0.02$ & $0.5 \pm 0.08$ \\
\hline$Y_{P X}(m g / g D W)$ & $1.18 \pm 0.12$ & $19.90 \pm 2$ \\
\hline$Y_{P S}(m g / g D W)$ & $0.214 \pm 0.02$ & $9.68 \pm 0.59$ \\
\hline$q_{s}(\mathrm{~g} \mathrm{gDW} / \mathrm{h})$ & $2.46 \pm 0.43$ & $0.23 \pm 0.02$ \\
\hline$q_{g l y}(g / g D W h)$ & $0.10 \pm 0.02$ & $0.001 \pm 3 \times 10^{-4}$ \\
\hline$a_{e t h}(g / g D W h)$ & $1.37 \pm 0.38$ & $0.002 \pm 1 \times 10^{-4}$ \\
\hline$a_{a c}(g / g D W h)$ & $0.1 \pm 0.02$ & $1 \times 10^{-4} \pm 1 \times 10^{-5}$ \\
\hline$a_{p}(\mathrm{~g} / \mathrm{gDW} \mathrm{h})$ & $0.38 \pm 0.02$ & $2.19 \pm 0.31$ \\
\hline $\mathrm{Q}_{p}(\mathrm{~g} / \mathrm{gDW} / \mathrm{h})$ & $0.22 \pm 0.02$ & $4.75 \pm 0.45$ \\
\hline$q_{\mathrm{O} 2}(\mathrm{mmol} / \mathrm{C}-\mathrm{mmol} / \mathrm{h})$ & $11.1 \pm 0.6$ & $0.96 \pm 0.07$ \\
\hline$a_{\mathrm{CO} 2}\left(\mathrm{mmolCO}_{2} / \mathrm{C}-\mathrm{mmol} / \mathrm{h}\right)$ & $15.02 \pm 0.78$ & $1.06 \pm 0.09$ \\
\hline $\mathrm{RQ}(-)$ & 0.70 & 1.11 \\
\hline \multicolumn{3}{|l|}{ Chemostat } \\
\hline$D\left(h^{-1}\right)$ & $0.048 \pm 0.003$ & $0.047 \pm 0.002$ \\
\hline Feeding solution (Cx in g/L) & 7.5 & 15 \\
\hline $\begin{array}{l}\text { Biomass concentration ( } C x \text { in } \\
\left.g_{D W} / L\right)\end{array}$ & $2.87 \pm 0.3$ & $3.62 \pm 0.3$ \\
\hline Residual substrate (g/L) & ND & $7.66 \pm 0.3$ \\
\hline p-coumaric acid (mg/L) & $2.23 \pm 0.04$ & $55.5 \pm 3$ \\
\hline$q_{s}(\mathrm{mmol} / \mathrm{gDW} / \mathrm{h})$ & $1.41 \pm 0.09$ & $0.55 \pm 0.02$ \\
\hline$a_{g / y}(\mathrm{mmol} / \mathrm{gDW} / \mathrm{h})$ & $2.54 \mathrm{E}^{-03}$ & ND \\
\hline$q_{\text {eth }}(\mathrm{mmol} / \mathrm{gDW} / \mathrm{h})$ & $1.70 \mathrm{E}^{-01}$ & ND \\
\hline$q_{a c}(\mathrm{mmol} / \mathrm{gDW} / \mathrm{h})$ & $2.84 \mathrm{E}^{-03}$ & ND \\
\hline$a_{\mathrm{O} 2}(\mathrm{mmol} / \mathrm{gDW} / \mathrm{h})$ & $0.25 \pm 0.02$ & $0.11 \pm 0.02$ \\
\hline$q_{\mathrm{CO} 2}(\mathrm{mmolCO} 2 / \mathrm{gDW} / \mathrm{h})$ & $0.22 \pm 0.22$ & $0.09 \pm 0.02$ \\
\hline $\mathrm{RQ}(-)$ & $1.13 \pm 0.03$ & $1.22 \pm 0.03$ \\
\hline Dissolved oxygen (\%) & $>80$ & $>80$ \\
\hline
\end{tabular}

Data are means from four independent fermentations $(n=4 \pm$ standard deviation, sd)

$R Q$ respiratory quotient, $N D$ not detected

their ability to take up extracellular xylose and synthesise biomass despite this carbon being suboptimal for the cell, relative to growth on glucose as well as there being a poor transport affinity for this pentose sugar. The downregulation of protein translation also corroborates the observation of the slower growth rate on xylose, as cells here may be re-allocating protein to optimise metabolism as opposed to growing quickly. The changes in oxidation and reduction processes also reflects cells undergoing respiratory metabolism as opposed to fermentative metabolism, as is the case when glucose is used [43]. 


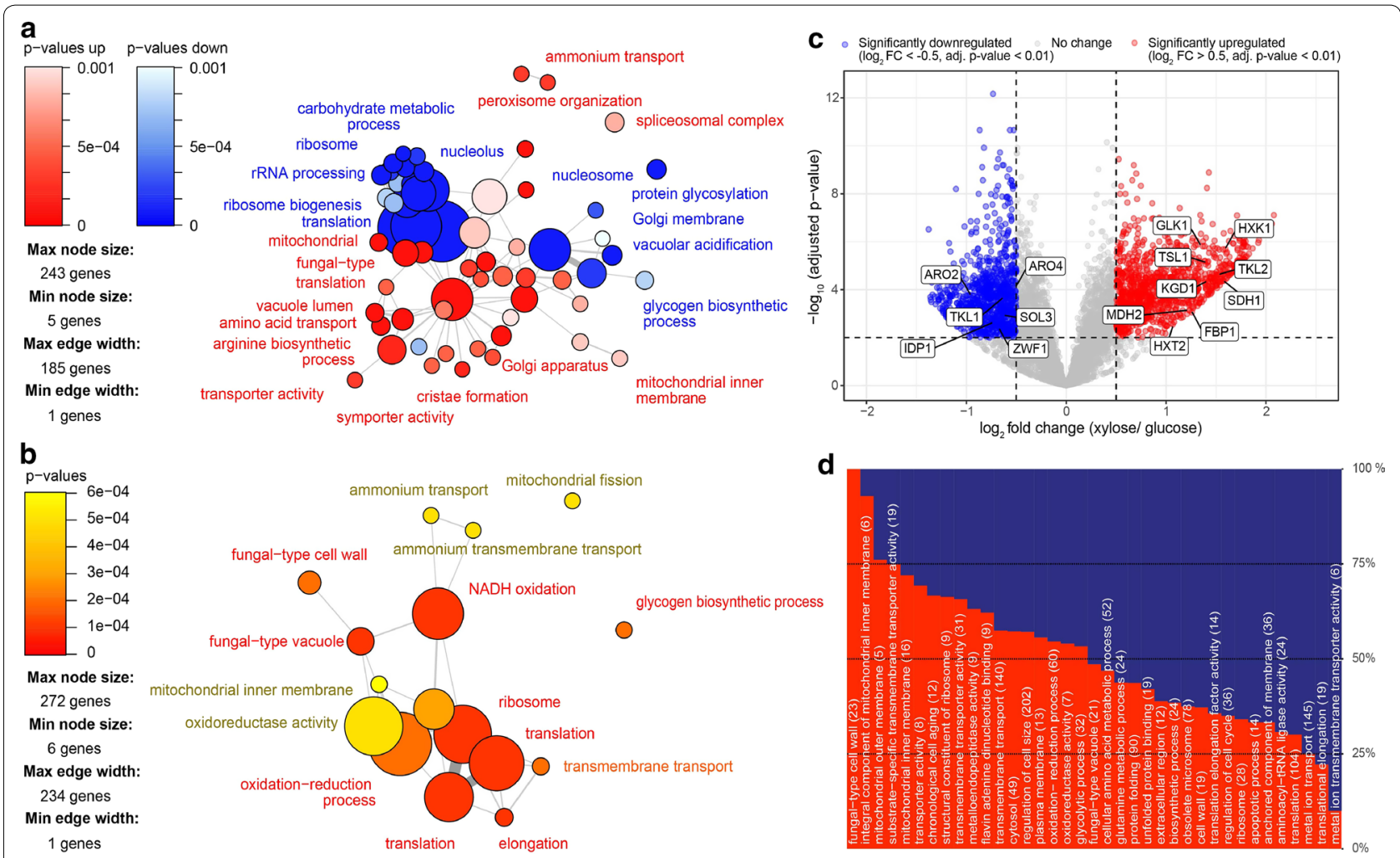

Fig. 2 Gene-set analysis (GSA) during glucose and xylose carbon limitation in chemostat cultures. Top panels a, b Gene sets were defined by gene ontology $(G O)$ terms, which show significant $(p<0.001)$ differential expression when grown on xylose compared to glucose. c The transcriptome profile under carbon limitation. X-axis specifies the $\log _{2}$ fold-change $\left(\log _{2} \mathrm{FC}\right)$ xylose/glucose, $y$-axis specifies the negative logarithm to the base $10 \mathrm{p}$-values. Red and blue points reflect the filtering criteria ( $\log _{2} \mathrm{FC}>0.5$ and $<-0.5$, and adjusted $p$-value $<0.01$ ). Grey dots represent genes without significant expression. Examples of several genes, which were significantly up or down regulated under xylose conditions are indicated and commented on further in the text. $\mathbf{d}$ Significantly $(p<0.01)$ enriched GO terms are shown in terms of percentage of genes either up- or downregulated under carbon limitation. The top upregulated GO terms are shown in red while the lower downregulated GO terms are shown in blue

To determine the role of central carbon metabolism, which generates the main building blocks for $p$-coumaric acid biosynthesis, these pathways specifically were examined further (Fig. 3). Here, significantly up-regulated transcripts were involved in respiration, in the tricarboxylic acid (TCA) cycle and glyoxylate pathway, correlating well with the observations found in the physiological data, which show an active respiratory system (Table 2). For example, in the glyoxylate pathway, ICL1 encoding isocitrate lyase, $M L S 1$ and $D A L 7$ encoding two malate synthases, and $M D H 2, M D H 3$ encoding two malate dehydrogenases were significantly up-regulated when ST4274 was grown on xylose. Additionally, the glyoxylate pathway had a similar up-regulation. This included succinate dehydrogenase, $\alpha$-ketoglutarate dehydrogenase and succinyl-CoA ligase $S D H 1, S D H 2, S D H 3, S D H 4, K G D 1$, $K G D 2$ and $L S C 2$, suggesting that the glyoxylate shunt is up-regulated during respiratory metabolism, which has also been shown previously [46]. We also found, two isoenzymes of isocitrate dehydrogenase $I D P 1$, fumarate reductase $F R D 1$ and mitochondrial malic enzyme $M A E 1$ to be significantly down-regulated in xylose limited conditions (Fig. 3a), supporting the hypothesis that the activity of the glyoxylate shunt is higher. This would suggest that cells adapt to growth on xylose by activating respiratory metabolism, and specifically the TCA cycle, bypassing some of this cycle by employing a glyoxylate shunt for, as yet, unclear reasons.

Together, these results indicate that strain ST4274, when cultivated on xylose, can utilize the glyoxylate shunt whilst concomitantly respiring using xylose, confirming this sugar as a non-fermentable carbon source. The upregulation of hexokinase 1, glucokinase, fructose-1,6-bisphosphatase, trehalose-6-phosphate synthase, and acid trehalase, i.e. HXK1, GLK1, FBP1, TSL1, TPS2, and ATH1 respectively, all indicate that cells have gluconeogenic activity [47]. A result that agrees with previous findings by Scalcinati et al. [43]. The up-regulation of phosphoglucomutase and UDP-glucose pyrophosphorylase, two isoenzymes of glycogen synthase and aquaglyceroporins 
PGM2, UGP1, GSY1, GSY2 and FPS1 also suggest that the cells are responding to xylose by accumulating storage carbohydrates, a starvation response phenotype. Indeed, this has been previously shown for slow growing respiring cells, indicative of cells utilising storage carbohydrates, such as trehalose and glycogen, to complete the cell cycle when nutrients are deprived [48-50]. This finding could explain why glucose transporters such as $H X T 2, H X T 5$, and $H X T 6$, are up-regulated during growth on xylose, as this would ensure maximum uptake. This is despite these transporters, which can uptake both carbon sources, having a lower affinity for xylose (Fig. 3a) [51, 52].

With respect to the pentose phosphate pathway (PPP), RNA expression levels suggest a lower flux through the oxidative branch, in particular as the three key enzymes glucose-6-phosphate dehydrogenase, 6-phosphogluconolactonase and 6-phosphogluconate dehydrogenase, encoded by $Z W F 1, S O L 3$, and GND1 respectively, had decreased expression compared to growth on glucose. On the other hand, transketolase TKL2 in the non-oxidative branch of the PPP, showed a significant up-regulation compared with cells grown on glucose (Figs. 2a, b, 3) [53]. In contrast, the expression levels of transketolase TKL1 and transaldolase TAL1 were reduced compared with glucose conditions, suggesting the switch from glucose to xylose metabolism affects enzymes in the PPP differently (Fig. 3). However, overall it appears that the flux through the PPP decreases upon switching to xylose (Fig. 3).

$p$-Coumaric acid is produced by Saccharomyces cerevisiae via the aromatic amino acid (AAA) "shikimate" pathway (Fig. 4). Here, phosphoenolpyruvate, PEP, and erythrose-4-phosphate, E4P, from glycolysis and the PPP respectively, are the primary substrates for two enzymes within the AAA pathway, specifically isoenzymes of DAHP synthase ARO3 and ARO4. DAHP is converted to shikimate, SHIK, via 3-dehydroquinate, DHQ, and 3-dehydroshikimate, 3-DHS. 3-DHS is then converted to 5-enolpyruvylshikimate 3-phosphate EPSP, with all reactions being catalyzed by the Penta-functional enzyme, ARO1. EPSP is then converted by chorismate synthase $A R O 2$, to chorismate, the precursor to all three aromatic amino acids, L-tryptophan, L-phenylalanine and L-tyrosine and subsequently to $p$-coumaric acid, from L-tyrosine. Interestingly, our RNA-seq data shows that for all reactions mentioned involving $A R O 3, A R O 4$, and $A R O 2$, the related transcripts are down-regulated (Fig. 3). This result was unexpected as it contrasts with observations found via physiological characterisation, specifically the higher production levels of $p$-coumaric acid under xylose conditions (Table 2). One explanation for this could be that post-transcriptional regulation has an influence in this pathway. Nonetheless, this data suggests that xylose imposes strong regulatory effects on the expression level of the shikimate pathway, a result that matches $\mathrm{GO}$ term enrichment analysis, which found general amino acid biosynthesis to be down regulated on switching to xylose [54]. A result indicative of this pathway enhancing $p$-coumaric acid production via post-transcriptional regulation.

\section{Discussion}

In this work, we report the first $S$. cerevisiae strain (ST4274) able to produce $p$-coumaric acid using xylose as the sole carbon source. Moreover, this strain achieved a 45-fold increase in titer of $p$-coumaric acid compared with production with glucose under our conditions (Table 2). Our physiological characterization is also consistent with transcriptome analysis of cells grown on xylose when focusing on central carbon metabolism (Fig. 3), with most significant GO-terms in the strain ST4274 being related to functions or features linked to respiratory processes, transport activities, biosynthetic processes and membrane functions (Fig. 2).

Physiological characterization under batch and chemostat conditions of the strain ST4274 presented low production rates of acetate, glycerol and ethanol compared to glucose condition (Table 2). The observed upregulation of the glyoxylate pathway on xylose condition correlates with low dilution rates in carbon-limited chemostats in S. cerevisiae suggesting that this phenomenon is not limited to growth on xylose but is a common feature of respiratory metabolism (that occurs at low dilution rates with carbon limitation) $[41,46,55]$.

On the one hand, ST4274 efficiently ferment glucose to produce ethanol by downregulating irrelevant metabolic pathways even though oxygen is present, this regulatory system is commonly defined as overflow metabolism or 'Crabtree effect.' On the other hand, employing nonfermentable sugars, such as xylose, ST4274 showed a respiratory metabolism, and an up-regulation of non-fermentative pathways redirecting the carbon flux through AAAs biosynthesis leading a higher production of $p$-coumaric acid. An active respiratory metabolism, higher biomass yield, and a clearly diminished overflow metabolism lead to a low ethanol rate on xylose $(\sim 0.002 \mathrm{~g} / \mathrm{gDW}$ h) compared to glucose $(1.37 \pm 0.38 \mathrm{~g} / \mathrm{gDW}$ h). Recent studies on recombinant $S$. cerevisiae strain engineered for 3-HP production has shown a twofold change in the specific yield on xylose [56]. A similar observation was found in the production of amorphadiene, sesquiterpene molecule, in xylose cultures with $S$. cerevisiae. After a metabolic engineering approach, lead a higher titer and yield of amorphadiene on xylose $(254.3 \pm 6.2 \mathrm{mg} / \mathrm{L}$, $6.25 \pm 0.15 \mathrm{mg} / \mathrm{g}$ xylose) compared to glucose condition $(120.2 \pm 4.3 \mathrm{mg} / \mathrm{L}, 2.82 \pm 0.10 \mathrm{mg} / \mathrm{g})$ [57]. Co-cultures of xylose and glucose are essential for an efficient conversion of lignocellulose, still, up-to-date most strains 


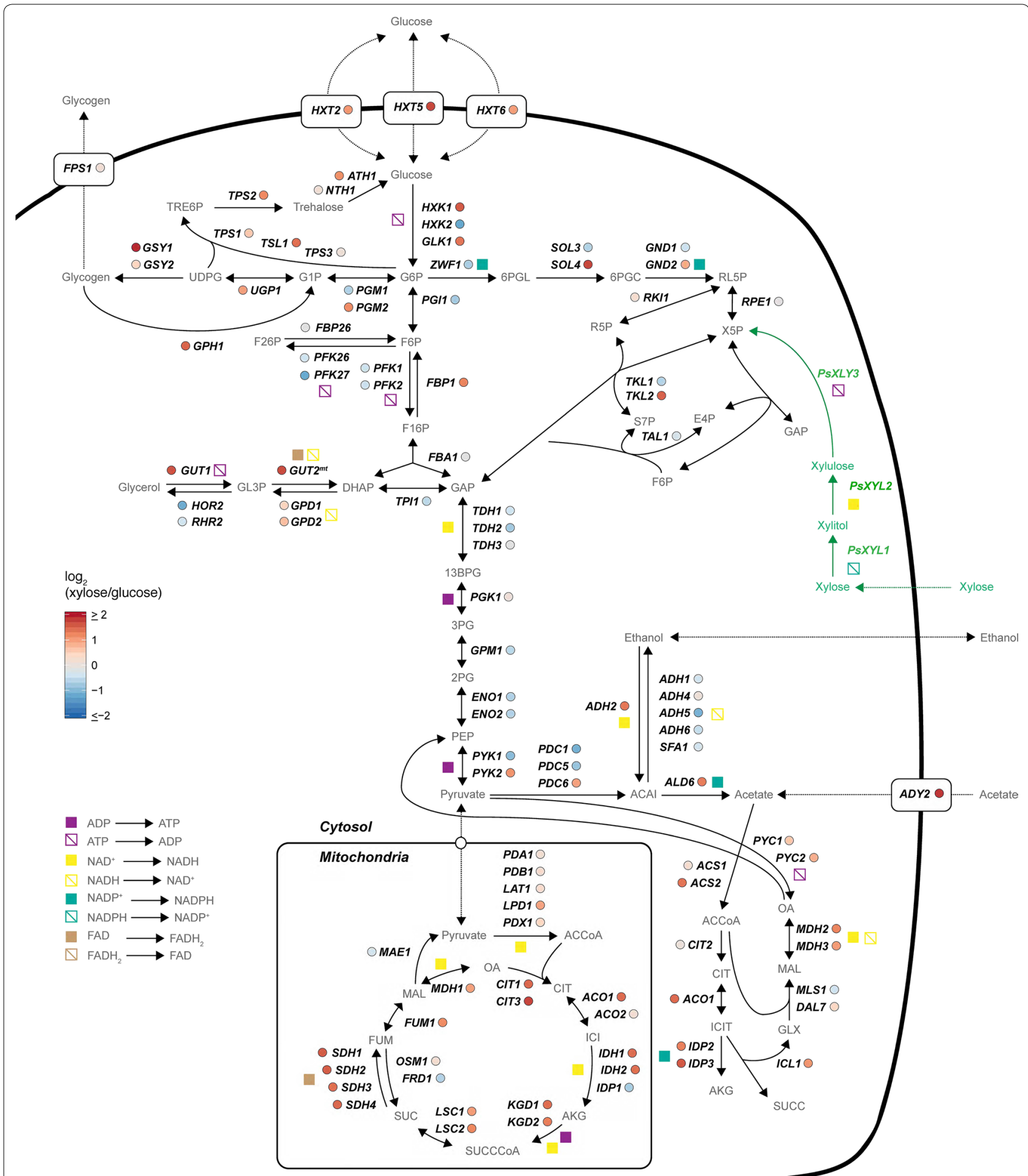

Fig. 3 Gene expression levels of central carbon metabolic pathways. Tricarboxylic acid (TCA) cycle, glyoxylate pathway, gluconeogenesis, glycogenesis and pentose phosphate pathway (PPP) are presented. The comparative analysis includes the $\log _{2}$ fold-change (log $F C$ ) xylose/glucose under carbon limitation conditions. The green label indicates overexpressed enzymes, "fbr" indicates feedback-resistant

exhibits glucose repression. To circumvent the glucose repression, co-cultures of xylose and cellobiose has been demonstrated to be feasible by Turner et al. with and engineered S. cerevisiae to produce value-added compounds from such as lactic acid reaching a titer of $83 \mathrm{~g} / \mathrm{L}$ with a yield of 0.66 lactic acid/g sugar with low yields of 
ethanol [58]. A clearly diminished Crabtree effect and a respiratory metabolism in S. cerevisiae grown on xylose or co-cultures wit xylose and cellobiose have presented a low production of ethanol. However, the metabolism of $S$. cerevisiae on xylose has been proven to be advantageous to produce above described value-added compounds instead of ethanol.

To enhance $p$-coumaric acid production, we overexpressed the feedback-resistant versions of Aro4p and Aro7p, which can both be feedback regulated by L-tyrosine. These and other modifications subsequently led to a significant increase in $p$-coumaric levels (42-fold higher than previously reported with glucose, and the first report of $p$-coumaric acid production with xylose as the sole carbon source). Contrastingly, when analysing the transcriptome of xylose cultured cells, we found that many genes in the aromatic amino acid pathway, generating precursors for $p$-coumaric acid, were downregulated. This suggests that cells respond to these modifications by downregulating native genes involved in aromatic amino acid production, including $A R O 4$ and $A R O 7$. A result, which suggests that aromatic amino acid levels are tightly regulated by the cell, at least at the transcriptional level, and that post-transcriptional regulation may predominate in this pathway.

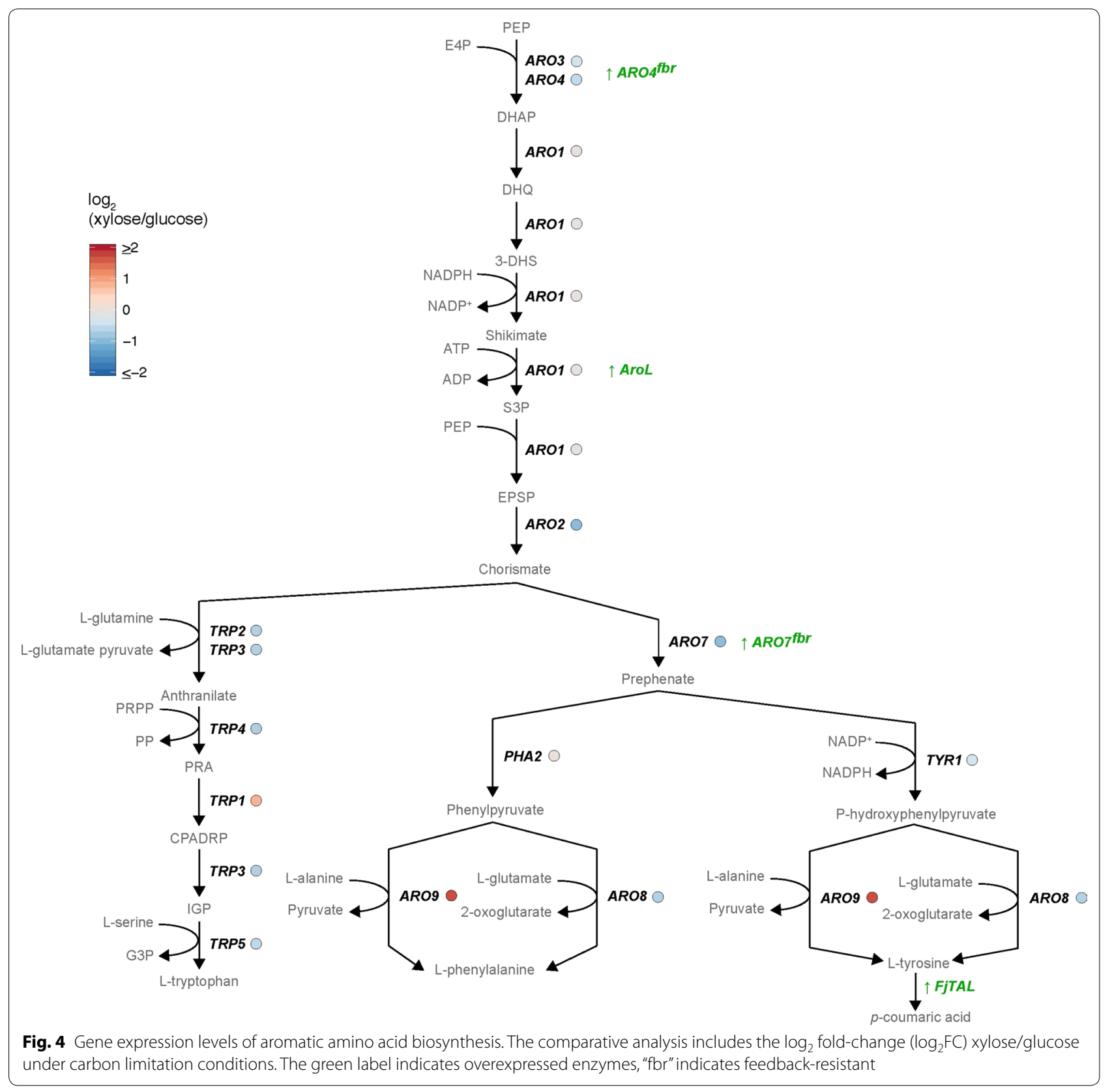




\section{Conclusion}

In conclusion, we designed a $p$-coumaric acid strain that presented a 45-fold increase compared to the same strain grown on glucose under the conditions we outline here. We also performed a transcriptome analysis to understand how the cell was able to re-wire its metabolism to enable $p$-coumaric acid production and found that cells produce this aromatic amino acid derivative by altering flux through central carbon metabolism, increasing storage carbohydrates, and in particular implementing respiratory metabolism.

\section{Materials and methods}

\section{Strains and plasmids}

All chemicals unless otherwise stated were purchased from Sigma-Aldrich (Merck). The E. coli strain DH5 $\alpha$ was used as a host for plasmid propagation and standard cloning; cells were grown at $37{ }^{\circ} \mathrm{C}$ in Luria-Bertani (LB) medium containing $100 \mathrm{mg} / \mathrm{L}$ ampicillin or $50 \mathrm{mg} / \mathrm{L}$ kanamycin. DNA fragments were amplified by PCR using primers as described in Table 3 . The biobricks are listed in Table 4. All engineered yeast strains and plasmids are described in Table 5, with all strains being constructed

Table 3 Primers used in this study

\begin{tabular}{|c|c|c|}
\hline ID & Name & Sequence \\
\hline \multicolumn{3}{|c|}{ Overexpression primers } \\
\hline 1691 & Fj_TAL_1_fw & AGTGCAGGUAAAACAATGAACACCATCAACGAATATCTGAGC \\
\hline 1692 & Fj_TAL_1_rv & CGTGCGAUTTAATTGTTAATCAGGTG \\
\hline 6785 & Ec_arol_2_fw & ATCTGTCAUAAAACAATGACACAACCTCTTTTTCTGA \\
\hline 6786 & Ec_aroL_2_rv & CACGCGAUTCAACAATTGATCGTCTGTGC \\
\hline 1398 & Sc_ARO7_1_fw & AGTGCAGGUAAAACAATGGATTTCACAAAACCAGAAAC \\
\hline 1399 & Sc_ARO7_1_rv & CGTGCGAUTCACTCTTCCAACCTTCTTAGCAAG \\
\hline 1396 & Sc_ARO4_2_fw & ATCTGTCAUAAAACAATGAGTGAATCTCCAATGTTCG \\
\hline 1397 & Sc_ARO4_2_rv & CACGCGAUTCATTTCTTGTTAACTTCTCTTCTTTG \\
\hline \multicolumn{3}{|c|}{ Verification primers } \\
\hline 904 & Sc_X-3-out-seq_rv & CCGTGCAATACCAAAATCG \\
\hline 906 & Sc_X-4-out-seq_rv & GACGGTACGTTGACCAGAG \\
\hline 912 & XI-3-down-out_rv & CACATTGAGCGAATGAAACG \\
\hline 2220 & Sc_ColoPCR_fw & CCTGCAGGACTAGTGCTGAG \\
\hline 1384 & Sc_PDC5_Start_fw & AAAGCCTCCATATCCAAAG \\
\hline 1385 & Sc_PDC5_End_rv & AGGTATGGTTAAAGATCACAC \\
\hline 1386 & Sc_ARO10_Start_fw & ACCGAAATTTAAAAAAGCAG \\
\hline 1387 & Sc_ARO10_End_rv & GTTTTCGGATAAAACTTCTTC \\
\hline \multicolumn{3}{|c|}{ Knockout primers } \\
\hline 1368 & Pdc5_UP_fw & CGTAAACCTGCATTAAG \\
\hline 1369 & Pdc5_UP_rv & GATCCCCGGGAATTGCCATTGTGTTGTTCTCTTTG \\
\hline 1370 & Pdc5_END_fw & GGTACCCAATTCGCCCTAGATTCAACGTTTGTGTA \\
\hline 1371 & Pdc5_END_rv & CTAAGATCATAGCTAAAGG \\
\hline 1372 & Aro10_UP_fw & GGATAGCCGTCATTTAC \\
\hline 1373 & Aro10_UP_rv & GATCCCCGGGAATTGCCAGAGGGTTGATCAGTTAAA \\
\hline 1374 & Aro10_END_fw & GGTACCCAATTCGCCCTACTACCAATTGTTCGTTT \\
\hline 1375 & Aro10_END_rv & CGATAGGAATGACAGAA \\
\hline 476 & KanMX_UP_fw & TGGCAATTCCCGGGGATCACGCTGC AGGTCGACAAC \\
\hline 477 & KanMX_UP_rv & AGTGACGACTGAATCCGGTG \\
\hline 478 & KanMX_END_fw & AATGGGCTCGCGATAATGTC \\
\hline 479 & KanMX_END_rv & TAGGGCGAATTGGGTACCGCCACTAGTGGA TCTGATATCAC \\
\hline 150 & LEU_UP_rv & CAGAAGCATAACTACCCATTCC \\
\hline 151 & LEU_END_FW & TGGAAGAGGCAAGCACGTTAGC \\
\hline 92 & URA3_2/3_START_rv & CGCTTCCCATCCAGCATTTC \\
\hline 93 & URA3_2/3_END_fw & CTGTCGTTCCATTGAAAGC \\
\hline
\end{tabular}


Table 4 Biobricks used in this study

\begin{tabular}{|c|c|c|c|}
\hline BioBrick ID & Template for PCR & Fw primer & Rv primer \\
\hline BB0380 (Fj_tal<-) & $\begin{array}{l}\text { F.johnsoniaeu codon-optimized } \\
\text { synthetic gene }\end{array}$ & Fj_Tal_U1_fw (ID1691) & Fj_TalU1_rv (ID1692) \\
\hline BB254 (KILEU2_2/3_START) & p0019(pUG73) & Sc_LEU2_2/3_START_fw (ID476) & SC_LEU2_2/3_START_rv (ID150) \\
\hline BB251 & CEN.PK113-7D gDNA & Sc_Pdc5_UP_fw (ID1368) & Sc_Pdc5_UP_rv (ID1369) \\
\hline BB252 & CEN.PK113-7D gDNA & Sc_Pdc5_END_fw (ID1370) & Sc_Pdc5_END_fw (ID1371) \\
\hline BB681 & CEN.PK113-7D gDNA & Sc_Aro10_UP_fw (1372) & Sc_Aro10_UP_rv (1373) \\
\hline BB0501 (EC_AroL->) & EcoMG1655 ATCC 31884 gDNA & Ec_AroL_U2_fw (ID6785) & Ec_AroL_U2_rv (ID6786) \\
\hline BB0361 (SC_Aro7_G141S<-) & p0761 (pESC-URA-ARO7pm) & Sc_aro7_U1_fw (ID1398) & Sc_aro7_U1_rv (ID1399) \\
\hline BB0364 (SC_Aro4_K229L->) & p0775 (pESC-HIS-ARO4pm) & Sc_aro4_U2_fw (ID1396) & Sc_aro4_U2_rv (ID1397) \\
\hline BB1189 (Pdc5_Up_kanmx_2/3 start) & p0015 (pUG6) & Pdc5_UP_fw (ID1368) & URA3_2/3_START_rv (ID92) \\
\hline BB1190(kanmx_2/3_end_Pdc5_down) & p0015 (pUG6) & URA3_2/3_END_fw (ID93) & Pdc5_END_rv (ID1371) \\
\hline BB828 (aro10_UP_Leu2_2/3_start) & BB251, BB245 & Sc_Aro10_UP_fw (1372) & Sc-LEU2_2/3_START_rv (ID150) \\
\hline BB829 (Leu2_2/3_end_aro10_down) & BB681, BB252 & LEU2_2/3_END_fw (ID151) & Aro10_END_rv (ID1375) \\
\hline
\end{tabular}

Table 5 Plasmids and strains used in this study

\begin{tabular}{|c|c|c|c|}
\hline Name & Parental plasmids & Description & Reference \\
\hline \multicolumn{4}{|l|}{ Plasmids } \\
\hline pCfB258 & $\ln$ & ntegrative plasmid, pX-4-loxP, SpHIS5, $\mathrm{P}_{T E F 1}-\mathrm{T}_{A D H 1}, \mathrm{P}_{G K p 1}-\mathrm{T}_{C Y C 1}$ & {$[21]$} \\
\hline pCfB390 & & ntegrative plasmid, pXI-3-IoxP, KIURA3, $\mathrm{P}_{T E F 1^{-T}} \mathrm{~T}_{A D H 1}, \mathrm{P}_{P G K 1}{ }^{-\top} \mathrm{CYC1}_{C Y}$ & $[21]]$ \\
\hline pCfB258 & & ntegrative plasmid, $\mathrm{pX}$-4-loxP, SpHIS5, $\mathrm{P}_{T E F 1}-\mathrm{T}_{A D H 1}, \mathrm{P}_{\mathrm{PGK1}} \mathrm{T}_{\mathrm{CYCl}}$ & {$[21]$} \\
\hline pCfB0826 & & $\begin{array}{l}\text { ntegrative plasmid, pX-4-LoXP, SpHiS5, } \mathrm{P}_{T E F 1}-\mathrm{SCArO} 7^{\mathrm{fbr}}-\mathrm{T}_{A D H 1} \\
\mathrm{P}_{P G K 1}-\mathrm{SCArO} 4^{\mathrm{fbr}}-\mathrm{T}_{C Y C 1}\end{array}$ & {$[44]$} \\
\hline pCfB1964 & & ntegrative plasmid, pX-2-loxP, KIURA3, $\mathrm{P}_{\mathrm{TEF} 1}-\mathrm{Fj}_{-} \mathrm{TAL}_{\mathrm{ADH} 1}$ & {$[44]$} \\
\hline pCfB2747 & pCfB3034 & ntegrative plasmid, X-3, $P_{\mathrm{PGK} 1}$ - EcaroL, KILEU2 & {$[44]$} \\
\hline pCfB3524 & pCfB390 & $\begin{array}{l}\text { ntegrative plasmid, pXI-3-loxP, KIURA3, BB380 (Fj_TAL }<-) \text {, } \\
\left.\text { BB010 (<- } P_{T E F 1}-P_{P G K 1}->\right), \text { BB0501 (EcaroL->) }\end{array}$ & This study \\
\hline Name & Description & Reference & \\
\hline \multicolumn{4}{|l|}{ Strains } \\
\hline ST2488 & 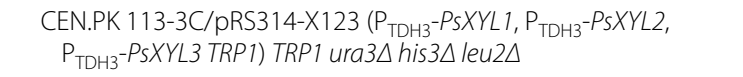 & {$[56]$} & \\
\hline ST4274 & 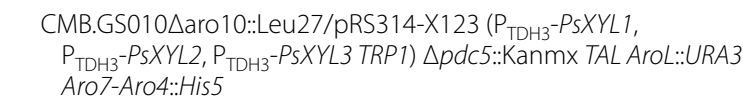 & This study & \\
\hline
\end{tabular}

from CMB.GS010 TRP1 ura3A his3A leu2A, originally derived from CEN.PK 113-7D [28]. The genetic modifications were performed by employing integrative EasyClone vectors with auxotrophic selection markers reported by Rodriguez [44]. The knockout strain $\Delta$ aro $10 \Delta p d c 5$ was constructed using a method based on a cloning-free, PCRbased allele replacement protocol by Erdeniz et al., which involved iterative replacement of these targeted genes with the cassettes KanMX and LEU2 in the background strain ST2488 [59]. For ARO10, the knockout fragments BB828 and BB829 were transformed into S. cerevisiae and the transformants were selected in synthetic complete (SC) leucine drop-out medium (SC-Leu). For the PDC5 knockout, the fragments BB1189 and BB1190 were transformed into the strain and the transformants were selected in SC medium supplemented with $200 \mathrm{mg} / \mathrm{L}$ G418 disulfate salt. Finally, the knockouts were confirmed by PCR on genomic DNA preparations, the LEU2 marker was looped-out and the plasmids PL826, PL1964 and PL2747 were integrated into the strain.

\section{Media and growth conditions}

All yeast strains were cultivated at $30{ }^{\circ} \mathrm{C}$ using $20 \mathrm{~g} / \mathrm{L}$ of either glucose or xylose as the carbon source in rich medium (YP, 1\% (w/v); Bacto yeast extract, $2 \%(\mathrm{w} / \mathrm{v})$ Bacto peptone), SC medium, or SC drop-out media (SCUra, SC-Leu, SC-His) with agar plates prepared using pre-mixed drop-out powder, supplemented with $20 \mathrm{~g} / \mathrm{L}$ 
agar. Minimal mineral (MM) medium for all fermentations was prepared as described previously [60], containing per litre: $25 \mathrm{~g}$ xylose or $25 \mathrm{~g}$ of glucose, $5 \mathrm{~g}\left(\mathrm{NH}_{4}\right)_{2} \mathrm{SO}_{4}$, $3 \mathrm{~g} \mathrm{KH}_{2} \mathrm{PO}_{4}, 0.5 \mathrm{~g} \mathrm{MgSO}_{4} \cdot 7 \mathrm{H} 2 \mathrm{O}, 0.1 \mathrm{~mL}$ antifoam 204 (Sigma A-8311), as well as $1 \mathrm{~mL}$ vitamin solution and $1 \mathrm{~mL}$ trace metal solution prepared as described previously [2]. The medium used for preparing inoculums in shake-flasks was the same as that for fermentations, with the following modifications: no antifoam, $7.5 \mathrm{~g} / \mathrm{L}$ $\left(\mathrm{NH}_{4}\right)_{2} \mathrm{SO}_{4}, 14.4 \mathrm{~g} / \mathrm{L} \mathrm{KH} \mathrm{PO}_{4}$ and the $\mathrm{pH}$ was adjusted to 6 with $\mathrm{KOH}$.

\section{Bioreactor cultivations}

All fermentations (batch and chemostat) were performed in controlled conditions and conducted in MM medium. A single colony of ST4274 was inoculated into $25 \mathrm{~mL}$ of MM medium supplemented with $2 \%$ of Glucose or Xylose as above, and incubated in $250-\mathrm{mL}$ baffled shake flasks at $30{ }^{\circ} \mathrm{C}$ with shaking $250 \mathrm{rpm}$ for $18 \mathrm{~h}$. Optical density $\mathrm{OD}_{600}$ was measured during the exponential phase and an appropriate volume of inoculum was spun down at $4000 \times g$ for $10 \mathrm{~min}$ at $4{ }^{\circ} \mathrm{C}$. Then the pellet was resuspended in $10 \mathrm{~mL}$ of fresh $\mathrm{MM}$ and used to inoculate the bioreactor with an initial $\mathrm{OD}_{600}$ of 0.05 . The batch and chemostat fermentations were performed in 1 L DASGIP Bioreactors (Dasgip, Jülich, Germany), with the following conditions for batch fermentation: working volume: $0.6 \mathrm{~L}$, temperature set-point: $30^{\circ} \mathrm{C}$, airflow: $1 \mathrm{vvm}$ (gas volume flow per unit of liquid volume per minute), $\mathrm{pH}$ : 6 (via feedback-controlled addition of $2 \mathrm{M} \mathrm{KOH}$ ), dissolved oxygen: $30 \%$ (via feedback control of agitation from $600 \mathrm{rpm}$ to a maximum of $1200 \mathrm{rpm}$ ). The concentration of $\mathrm{O}_{2}$ and $\mathrm{CO}_{2}$ in the exhaust gas was monitored by a DASGIP ${ }^{\circledR}$ GA4 exhaust analyser. Chemostat fermentations were preceded by a batch fermentation, under the same conditions of temperature, $\mathrm{pH}$ and stirring conditions as previously mentioned. After glucose and xylose had been depleted by a drop in the $\mathrm{CO}_{2}$ production rate, the fermentations were switched to chemostat mode yielding a dilution rate $(D)$ of $0.05 \mathrm{~h}^{-1}$ with a feeding solution of $7.5 \mathrm{~g} / \mathrm{L}$ of glucose and $15 \mathrm{~g} / \mathrm{L}$ of xylose. The working volume was kept constant at 0.6 $\mathrm{L}$ with an overflow system that continuously removed excess medium. To ensure cells were growing at a steadystate, chemostats were run for at least four residence times before sampling at a dilution rate of $0.05 \mathrm{~h}^{-1}$. Here, after $80 \mathrm{~h}$ of chemostat cultivation, samples were taken for cell dry weight (CDW), $p$-coumaric acid and organic acid quantification as well as RNA sequencing. CDW was determined in duplicate by filtering $15 \mathrm{~mL}$ of cell broth through dried, pre-weighed $0.45 \mu \mathrm{m}$ polyethersulfone (PES) membranes (Sartorius Stedim, Aubagne, France) and washing with deionized water. Membranes were then dried in a microwave oven at $120 \mathrm{~W}$ for $15 \mathrm{~min}$ and placed in a silica gel desiccator for a minimum of $12 \mathrm{~h}$ before re-weighing.

\section{Quantification of sugars, extracellular metabolites and $p$-coumaric acid}

Samples withdrawn from bioreactor cultures were filtered using $0.2 \mu \mathrm{m}$ nylon filters then immediately stored at $-20{ }^{\circ} \mathrm{C}$ before analysis. Glucose, xylose and extracellular metabolites (acetate, ethanol, glycerol, pyruvate, and succinate) were analyzed using high-performance liquid chromatography (HPLC; Ultimate 3000, Dionex, Sunnyvale, CA, USA) using an Aminex HPX87-H column (Bio-Rad Laboratories, Munich, Germany). Mobile phase (eluent) used was $5 \mathrm{mM} \mathrm{H}_{2} \mathrm{SO}_{4}(0.6 \mathrm{~mL} / \mathrm{min})$, with the column temperature maintained at $45{ }^{\circ} \mathrm{C}$. Ethanol, glucose, and glycerol were analyzed using a refractive index detector (Shodex RI-101, Showa Denko, New York, NY, USA), while acetate was analyzed using the UV detector set at $210 \mathrm{~nm}$. Six-point standard curves were set for quantification. Evaporation of ethanol was compensated for by assuming an evaporation rate of $0.0068 \mathrm{mmol}_{\text {ethanol evaporated }}$ $\mathrm{mmol}_{\text {ethanol in solution }}{ }^{-1} \mathrm{~h}^{-1}$, of the ethanol present at each specific time point [61].

In order to quantify $p$-coumaric acid, samples were withdrawn from the bioreactor during the time course cultivation $(1 \mathrm{~mL}$ each) then diluted 1:1 with absolute ethanol $(100 \% \mathrm{v} / \mathrm{v})$. After dilution, samples were spun down at max speed $(10,000 \mathrm{rpm})$. Quantification of $p$-coumaric acid was performed on HPLC (Thermo), equipped with a Discovery HS F5 $150 \mathrm{~mm} \times 2.1 \mathrm{~mm}$ column (particle size $3 \mathrm{~mm}$ ) according to Rodriguez et al. and the area under the peak was integrated with Chromeleon 7 and used for quantification by fitting with a standard curve [44].

\section{RNA sequencing}

Concentration and quality of the nucleic acids prior to sequencing were determined using a Qubit 2.0 fluorometer (Invitrogen) and an Agilent 2100 Bioanalyzer (Agilent Technologies) respectively. Sequencing libraries were prepared in triplicates using a TruSeq stranded mRNA Sample Preparation kit (Illumina Inc., San Diego $\mathrm{CA}$ ) and were pooled together before sequencing. An average cDNA library size was determined using the Agilent DNA 1000 kit on an Agilent 2100 Bioanalyzer. Normalized libraries were combined in $10 \mathrm{mM}$ Tris$\mathrm{Cl}$ at $\mathrm{pH} 8$, tween $20(0.05 \%)$ to a final concentration of $10 \mathrm{nM}$, then libraries were denatured in $0.2 \mathrm{~N} \mathrm{NaOH}$. A pool of $1.3 \mathrm{pM}$ of each library was resuspended in $1.3 \mathrm{~mL}$ ice-cold HT1 buffer, then loaded onto the flow cell provided in the NextSeq 500/550 High Output kit v2 (300 cycles) and sequenced on a NextSeq ${ }^{\circledR}$ (Illumina 
Inc., San Diego CA) platform with a paired-end protocol and read lengths of $151 \mathrm{nt}$. Reads were aligned on the yeast genome by using Bowtie2 [62] and further processed by SAMTools [51] and BEDTools [63] to count the number of reads aligning to each gene. Differential gene expression was analyzed using the DEseq package in $R$ programming language [64].

\section{Differential mRNA expression}

Differential expression was determined for strain ST4274 using fold change in transcript abundance when cells were grown on xylose relative to the glucose reference condition. The $\mathrm{p}$ values were adjusted for multiple testing using Benjamini-Hochberg procedure [65] as implemented in DESeq. Threshold values for differentially expressed mRNAs were adjusted to $\mathrm{p}<0.01$ and $\mathrm{a}>0.5,<-0.5 \log _{2}$ fold change (FC) for both up and down regulated genes was applied. A list of differentially expressed genes were annotated with gene ontology (GO) terms (Process, Function and Component) using the Bioconductor $\mathrm{R}$ package BioMaRt to access the Ensembl Saccharomyces cerevisiae gene data set and the list of the GO names (name 1006) for each ensemble gene ID. Gene set analysis and networkbased plots of overlapping gene sets and their significance were generated with the Bioconductor R package piano [66]. Volcano plots for visualising $\log _{2}$ FC versus their significance was performed using the $R$ package ggplot2 [67].

\section{Acknowledgements}

The authors thank Fredrik Schubert and Eduard J. Kerkhoven for assistance during chemostat cultivations. Also, to Ibrahim Elsemman for providing the assistance with the transcriptomic discussion.

\section{Authors' contributions}

GMBZ performed all the fermentation experiments, the omics analysis and analysed the data. AR constructed the strains. KC assisted with data analysis and drafting of the manuscript. $Y C$ and IB supervised the work. JN conceived the project and provided funding. GMBZ wrote the manuscript. All authors contributed to editing the manuscript. All authors read and approved the final manuscript.

\section{Funding}

This work was financed by the Novo Nordisk Foundation (Grant No. NNF10CC1016517) and CONACyT. IB acknowledges the financial support from the European Union's Horizon 2020 research and innovation programme under Grant Agreement No. 814408 (SHIKIFACTORY100).

\section{Availability of data and materials}

The generated RNAseq and fermentations datasets from this current study are available from the corresponding author on reasonable request.

Ethics approval and consent to participate

Not applicable.

\section{Consent for publication}

Not applicable.

\section{Competing interests}

The authors declare that they have no competing interests.

\section{Author details}

${ }^{1}$ The Novo Nordisk Foundation Center for Biosustainability, Technical University of Denmark, 2800 Lyngby, Denmark. ${ }^{2}$ Department of Biology and Biological Engineering, Chalmers University of Technology, 41296 Gothenburg, Sweden. ${ }^{3}$ Biolnnovation Institute, Ole Måløes Vej 3, 2200 Copenhagen N, Denmark. ${ }^{4}$ Present Address: The Bioinformatics Centre, Section for Computational and RNA Biology, Department of Biology, Faculty of Science, University of Copenhagen, Ole Maaloes Vej 5, 2200 Copenhagen, Denmark.

Received: 5 April 2019 Accepted: 27 October 2019

Published online: 05 November 2019

\section{References}

1. Becker J, Wittmann C. Systems and synthetic metabolic engineering for amino acid production - the heartbeat of industrial strain development. Curr Opin Biotechnol. 2012;23:718-26.

2. Lahtvee PJ, Sanchez BJ, Smialowska A, Kasvandik S, Elsemman IE, Gatto F, Nielsen J. Absolute quantification of protein and mRNA abundances demonstrate variability in gene-specific translation efficiency in yeast. Cell Syst. 2017;4(495-504):e495.

3. Zhang H, Stephanopoulos G. Engineering E. coli for caffeic acid biosynthesis from renewable sugars. Appl Microbiol Biotechnol. 2013:97:3333-41.

4. Masuo S, Zhou S, Kaneko T, Takaya N. Bacterial fermentation platform for producing artificial aromatic amines. Sci Rep. 2016;6:25764.

5. Rodriguez A, Martinez JA, Flores N, Escalante A, Gosset G, Bolivar F. Engineering Escherichia coli to overproduce aromatic amino acids and derived compounds. Microb Cell Fact. 2014;13:126.

6. Ramos-Gonzalez MI, Ben-Bassat A, Campos MJ, Ramos JL. Genetic engineering of a highly solvent-tolerant Pseudomonas putida strain for biotransformation of toluene to $p$-hydroxybenzoate. Appl Environ Microbiol. 2003;69:5120-7.

7. Kallscheuer N, Vogt M, Stenzel A, Gatgens J, Bott M, Marienhagen J. Construction of a Corynebacterium glutamicum platform strain for the production of stilbenes and (2S)-flavanones. Metab Eng. 2016;38:47-55.

8. Tsuge Y, Kawaguchi H, Sasaki K, Kondo A. Engineering cell factories for producing building block chemicals for bio-polymer synthesis. Microb Cell Fact. 2016;15:19.

9. Appelhagen I, Wulff-Vester AK, Wendell M, Hvoslef-Eide AK, Russell J, Oertel A, Martens S, Mock HP, Martin C, Matros A. Colour bio-factories: towards scale-up production of anthocyanins in plant cell cultures. Metab Eng. 2018;48:218-32.

10. Tieman D, Taylor M, Schauer N, Fernie AR, Hanson AD, Klee HJ. Tomato aromatic amino acid decarboxylases participate in synthesis of the flavor volatiles 2-phenylethanol and 2-phenylacetaldehyde. Proc Natl Acad Sci USA. 2006;103:8287-92.

11. Ouyang J, Shao X, Li J. Indole-3-glycerol phosphate, a branchpoint of indole-3-acetic acid biosynthesis from the tryptophan biosynthetic pathway in Arabidopsis thaliana. Plant J. 2000;24:327-33.

12. Rodriguez A, Chen Y, Khoomrung S, Ozdemir E, Borodina I, Nielsen J. Comparison of the metabolic response to over-production of $p$-coumaric acid in two yeast strains. Metab Eng. 2017:44:265-72.

13. Krivoruchko A, Siewers V, Nielsen J. Opportunities for yeast metabolic engineering: lessons from synthetic biology. Biotechnol J. 2011;6:262-76.

14. Lian J, Mishra S, Zhao H. Recent advances in metabolic engineering of Saccharomyces cerevisiae: new tools and their applications. Metab Eng. 2018;50:85-108.

15. Rodriguez-Limas WA, Tyo KE, Nielsen J, Ramirez OT, Palomares LA. Molecular and process design for rotavirus-like particle production in Saccharomyces cerevisiae. Microb Cell Fact. 2011;10:33.

16. de Ruijter JC, Jurgens G, Frey AD. Screening for novel genes of Saccharomyces cerevisiae involved in recombinant antibody production. FEMS Yeast Res. 2017. https://doi.org/10.1093/femsyr/fow104. 
17. Liu L, Martinez JL, Liu Z, Petranovic D, Nielsen J. Balanced globin protein expression and heme biosynthesis improve production of human hemoglobin in Saccharomyces cerevisiae. Metab Eng. 2014;21:9-16.

18. Tippmann S, Anfelt J, David F, Rand JM, Siewers V, Uhlen M, Nielsen J, Hudson EP. Affibody scaffolds improve sesquiterpene production in Saccharomyces cerevisiae. ACS Synth Biol. 2017;6:19-28.

19. Tippmann S, Chen Y, Siewers V, Nielsen J. From flavors and pharmaceuticals to advanced biofuels: production of isoprenoids in Saccharomyces cerevisiae. Biotechnol J. 2013:8:1435-44.

20. Agren R, Otero JM, Nielsen J. Genome-scale modeling enables metabolic engineering of Saccharomyces cerevisiae for succinic acid production. J Ind Microbiol Biotechnol. 2013;40:735-47.

21. Jensen NB, Strucko T, Kildegaard KR, David F, Maury J, Mortensen UH, Forster J, Nielsen J, Borodina I. EasyClone: method for iterative chromosomal integration of multiple genes in Saccharomyces cerevisiae. FEMS Yeast Res. 2014;14:238-48

22. Jessop-Fabre MM, Jakociunas T, Stovicek V, Dai Z, Jensen MK, Keasling JD, Borodina I. EasyClone-MarkerFree: a vector toolkit for marker-less integration of genes into Saccharomyces cerevisiae via CRISPR-Cas9. Biotechnol J. 2016:11:1110-7

23. Stovicek V, Borja GM, Forster J, Borodina I. EasyClone 2.0: expanded toolkit of integrative vectors for stable gene expression in industrial Saccharomyces cerevisiae strains. J Ind Microbiol Biotechnol. 2015;42:1519-31.

24. Campbell K, Xia J, Nielsen J. The impact of systems biology on bioprocessing. Trends Biotechnol. 2017:35:1156-68.

25. Caspeta L, Nielsen J. Thermotolerant yeast strains adapted by laboratory evolution show trade-off at ancestral temperatures and preadaptation to other stresses. MBio. 2015;6:e00431.

26. Lahtvee PJ, Kumar R, Hallstrom BM, Nielsen J. Adaptation to different types of stress converge on mitochondrial metabolism. Mol Biol Cell. 2016;27:2505-14

27. Fletcher E, Feizi A, Bisschops MM, Hallstrom BM, Khoomrung S, Siewers V, Nielsen J. Evolutionary engineering reveals divergent paths when yeast is adapted to different acidic environments. Metab Eng. 2017;39:19-28.

28. Kildegaard KR, Hallstrom BM, Blicher TH, Sonnenschein N, Jensen NB, Sherstyk S, Harrison SJ, Maury J, Herrgard MJ, Juncker AS, et al. Evolution reveals a glutathione-dependent mechanism of 3-hydroxypropionic acid tolerance. Metab Eng. 2014;26:57-66.

29. Borodina I, Nielsen J. From genomes to in silico cells via metabolic networks. Curr Opin Biotechnol. 2005;16:350-5.

30. Borodina I, Nielsen J. Advances in metabolic engineering of yeast Saccharomyces cerevisiae for production of chemicals. Biotechnol J. 2014;9:609-20.

31. Hong KK, Nielsen J. Metabolic engineering of Saccharomyces cerevisiae: a key cell factory platform for future biorefineries. Cell Mol Life Sci. 2012;69:2671-90

32. Luttik MA, Vuralhan Z, Suir E, Braus GH, Pronk JT, Daran JM. Alleviation of feedback inhibition in Saccharomyces cerevisiae aromatic amino acid biosynthesis: quantification of metabolic impact. Metab Eng. 2008;10:141-53.

33. Li M, Kildegaard KR, Chen Y, Rodriguez A, Borodina I, Nielsen J. De novo production of resveratrol from glucose or ethanol by engineered Saccharomyces cerevisiae. Metab Eng. 2015;32:1-11.

34. Koopman F, Beekwilder J, Crimi B, van Houwelingen A, Hall RD, Bosch D, van Maris AJ, Pronk JT, Daran JM. De novo production of the flavonoid naringenin in engineered Saccharomyces cerevisiae. Microb Cell Fact. 2012:11:155.

35. Li M, Schneider K, Kristensen M, Borodina I, Nielsen J. Engineering yeast for high-level production of stilbenoid antioxidants. Sci Rep. 2016;6:36827.

36. Minami H, Kim JS, Ikezawa N, Takemura T, Katayama T, Kumagai H, Sato F. Microbial production of plant benzylisoquinoline alkaloids. Proc Natl Acad Sci USA. 2008;105:7393-8.

37. Li Y, Li S, Thodey K, Trenchard I, Cravens A, Smolke CD. Complete biosynthesis of noscapine and halogenated alkaloids in yeast. Proc Natl Acad Sci USA. 2018:115:E3922-31.

38. Pfeiffer T, Morley A. An evolutionary perspective on the Crabtree effect. Front Mol Biosci. 2014;1:17

39. Campbell K, Herrera-Dominguez L, Correia-Melo C, Zelezniak A, Ralser M. Biochemical principles enabling metabolic cooperativity and phenotypic heterogeneity at the single cell level. Curr Opin Syst Biol. 2018;8:97-108

40. Olsson L, Nielsen J. The role of metabolic engineering in the improvement of Saccharomyces cerevisiae: utilization of industrial media. Enzyme Microb Technol. 2000;26:785-92.

41. van Maris AJ, Winkler AA, Kuyper M, de Laat WT, van Dijken JP, Pronk JT. Development of efficient xylose fermentation in Saccharomyces cerevisiae: xylose isomerase as a key component. Adv Biochem Eng Biotechnol. 2007:108:179-204.

42. Van Vleet JH, Jeffries TW. Yeast metabolic engineering for hemicellulosic ethanol production. Curr Opin Biotechnol. 2009;20:300-6.

43. Scalcinati G, Otero JM, Van Vleet JR, Jeffries TW, Olsson L, Nielsen J. Evolutionary engineering of Saccharomyces cerevisiae for efficient aerobic xylose consumption. FEMS Yeast Res. 2012;12:582-97.

44. Rodriguez A, Kildegaard KR, Li M, Borodina I, Nielsen J. Establishment of a yeast platform strain for production of $p$-coumaric acid through metabolic engineering of aromatic amino acid biosynthesis. Metab Eng. 2015;31:181-8.

45. Jendresen CB, Stahlhut SG, Li M, Gaspar P, Siedler S, Forster J, Maury J, Borodina I, Nielsen AT. Highly active and specific tyrosine ammonialyases from diverse origins enable enhanced production of aromatic compounds in bacteria and Saccharomyces cerevisiae. Appl Environ Microbiol. 2015;81:4458-76.

46. Regenberg B, Grotkjaer T, Winther O, Fausboll A, Akesson M, Bro C, Hansen LK, Brunak S, Nielsen J. Growth-rate regulated genes have profound impact on interpretation of transcriptome profiling in Saccharomyces cerevisiae. Genome Biol. 2006;7:R107.

47. Ma Q, Wang C, Jones D, Quintanilla KE, Li D, Wang Y, Wieder ED, Clise-Dwyer K, Alatrash G, Mj Y, et al. Adoptive transfer of PR1 cytotoxic T lymphocytes associated with reduced leukemia burden in a mouse acute myeloid leukemia xenograft model. Cytotherapy. 2010;12:1056-62

48. Francois J, Parrou JL. Reserve carbohydrates metabolism in the yeast Saccharomyces cerevisiae. FEMS Microbiol Rev. 2001;25:125-45.

49. Beese SE, Negishi T, Levin DE. Identification of positive regulators of the yeast fps1 glycerol channel. PLoS Genet. 2009:5:e1000738.

50. Ewald JC, Kuehne A, Zamboni N, Skotheim JM. The yeast cyclin-dependent kinase routes carbon fluxes to fuel cell cycle progression. Mol Cell. 2016;62:532-45.

51. Rintala E, Wiebe MG, Tamminen A, Ruohonen L, Penttila M. Transcription of hexose transporters of Saccharomyces cerevisiae is affected by change in oxygen provision. BMC Microbiol. 2008;8:53.

52. Ozcan S, Johnston M. Function and regulation of yeast hexose transporters. Microbiol Mol Biol Rev. 1999;63:554-69.

53. Matsushika A, Inoue H, Kodaki T, Sawayama S. Ethanol production from xylose in engineered Saccharomyces cerevisiae strains: current state and perspectives. Appl Microbiol Biotechnol. 2009;84:37-53.

54. Natarajan K, Meyer MR, Jackson BM, Slade D, Roberts C, Hinnebusch AG, Marton MJ. Transcriptional profiling shows that Gcn4p is a master regulator of gene expression during amino acid starvation in yeast. Mol Cell Biol. 2001:21:4347-68.

55. Daran-Lapujade P, Jansen ML, Daran JM, van Gulik W, de Winde JH, Pronk JT. Role of transcriptional regulation in controlling fluxes in central carbon metabolism of Saccharomyces cerevisiae. A chemostat culture study. J Biol Chem. 2004:279:9125-38.

56. Kildegaard KR, Wang Z. YunChen, Nielsen J, IrinaBorodina: production of 3-hydroxypropionic acid from glucose and xylose by metabolically engineered Saccharomyces cerevisiae. Metab Eng Commun. 2015;2:132-6.

57. Kwak S, Kim SR, Xu H, Zhang GC, Lane S, Kim H, Jin YS. Enhanced isoprenoid production from xylose by engineered Saccharomyces cerevisiae. Biotechnol Bioeng. 2017;114:2581-91

58. Turner TL, Zhang GC, Oh EJ, Subramaniam V Adiputra A, Subramaniam V, Skory CD, Jang JY, Yu BJ, Park I, Jin YS. Lactic acid production from cellobiose and xylose by engineered Saccharomyces cerevisiae. Biotechnol Bioeng. 2016;113:1075-83.

59. Erdeniz N, Mortensen UH, Rothstein R. Cloning-free PCR-based allele replacement methods. Genome Res. 1997;7:1174-83.

60. Verduyn C, Postma E, Scheffers WA, Van Dijken JP. Effect of benzoic acid on metabolic fluxes in yeasts: a continuous-culture study on the regulation of respiration and alcoholic fermentation. Yeast. 1992;8:501-17. 
61. Cueto-Rojas HF, Maleki Seifar R, Ten Pierick A, Heijnen SJ, Wahl A. Accurate measurement of the in vivo ammonium concentration in Saccharomyces cerevisiae. Metabolites. 2016;6:12.

62. Langmead B, Salzberg SL. Fast gapped-read alignment with Bowtie 2. Nat Methods. 2012;9:357-9.

63. Li H, Handsaker B, Wysoker A, Fennell T, Ruan J, Homer N, Marth G, Abecasis G, Durbin R. Genome project data processing S: the sequence alignment/map format and SAMtools. Bioinformatics. 2009;25:2078-9.

64. Anders S, Huber W. Differential expression analysis for sequence count data. Genome Biol. 2010;11:R106.

65. Benjamini Y, Drai D, Elmer G, Kafkafi N, Golani I. Controlling the false discovery rate in behavior genetics research. Behav Brain Res. 2001;125:279-84.

66. Varemo L, Nielsen J, Nookaew I. Enriching the gene set analysis of genome-wide data by incorporating directionality of gene expression and combining statistical hypotheses and methods. Nucleic Acids Res. 2013;41:4378-91.

67. Wickham H. ggplot2 elegant graphics for data analysis. 2nd ed. Berlin: Springer International Publishing; 2016.

68. Liao JC, Mi L, Pontrelli S, Luo S. Fuelling the future: microbial engineering for the production of sustainable biofuels. Nat Rev Microbiol. 2016;14:288.
69. McKenna R, Thompson B, Pugh S, Nielsen DR. Rational and combinatorial approaches to engineering styrene production by Saccharomyces cerevisiae. Microb Cell Fact. 2014;13:123.

70. Verhoef S, Wierckx N, Westerh of RG, de Winde JH, Ruijssenaars HJ. Bioproduction of $\mathrm{p}$-hydroxystyrene from glucose by the solvent-tolerant bacterium Pseudomonas putida S12 in a two-phase water-decanol fermentation. Appl Environ Microbiol. 2009;75:931-6.

71. Zhang H, Pereira B, Li Z, Stephanopoulos G. Engineering Escherichia coli coculture systems for the production of biochemical products. Proc Natl Acad Sci USA. 2015;112:8266-71.

72. Averesch NJ, Winter G, Kromer JO. Production of para-aminobenzoic acid from different carbon-sources in engineered Saccharomyces cerevisiae. Microb Cell Fact. 2016;15:89.

\section{Publisher's Note}

Springer Nature remains neutral with regard to jurisdictional claims in published maps and institutional affiliations.
Ready to submit your research? Choose BMC and benefit from:

- fast, convenient online submission

- thorough peer review by experienced researchers in your field

- rapid publication on acceptance

- support for research data, including large and complex data types

- gold Open Access which fosters wider collaboration and increased citations

- maximum visibility for your research: over 100M website views per year

At BMC, research is always in progress.

Learn more biomedcentral.com/submissions 